DOI: 10.4322/978-65-89910-16-9-02

\title{
ISS - IMPOSTO SOBRE SERVIÇO: LEGISLAÇÃO E ARRECADAÇÃO NO MUNICÍPIO DE BACABAL/MA
}

Francisco José de Oliveira Veiga ${ }^{7}$ Jenifer Thauane da Silva Aragão ${ }^{8}$ Mauro Leray ${ }^{9}$ Natália Borges de Sousa ${ }^{10}$ Roniely Cristina Morais dos Santos ${ }^{11}$

\footnotetext{
7 Administrador e especialista em Gestão Pública. E-mail: adm.franciscoveiga@hotmail.com

8 Discente do curso de Administração da Faculdade Edufor. E-mail: jeniferthauane.red@gmail.com

${ }^{9}$ Docente da Faculdade Edufor. E-mail: mauro.leray@edufor.edu.br

10 Administradora, especialista em Metodologia do Ensino Superior e especialista em Gestão Pública. E-mail: nataliaborgesadm@hotmail.com ${ }^{11}$ Administradora e Supervisora Administrativa da Faculdade Edufor. E-mail: roniely.cristina@edufor.edu.br
} 


\section{RESUMO}

O Imposto sobre Serviços é um tributo de competência municipal e do Distrito Federal, tendo como fato gerador a prestação de serviços, como contribuinte o prestador do serviço e por base de cálculo o preço do serviço. O estudo desse tema mostra-se relevante e atual pelo fato de nos levar ao aprofundamento do Imposto sobre Serviços, sua legislação e a forma como é arrecadado. Tem como objetivo principal apresentar a legislação pertinente e recolhimento no município de Bacabal - MA apoiado nos objetivos específicos de identificar no portal de transparência os valores arrecadados, descrever a legislação e demonstrar a importância desse imposto para o município. Almejando assim responder 0 questionamento: Como é regido e arrecadado o Imposto sobre Serviços no município de Bacabal - MA? Os estudos e considerações deste artigo passam pela conceituação das ciências dos tributos, da Administração Pública e da legislação municipal. Embasamos a pesquisa bibliográfica e documental com autores como Crepaldi (2017), Hack (2013), Gomes (2010), assim como as legislações como Lei Complementar no116, a Constituição Federal de 1988, outras leis estaduais e municipais e também os dados do portal de transparência do município e do Instituto Brasileiro de Geografia e Estatística. O Imposto sobre Serviço no município de Bacabal - MA é regido pela Lei 1.082 de 2008 que dispõe sobre os tributos municipais, arrecadação e alíquota e outras observações. Segundo os dados encontrados na pesquisa no portal de transparência do município o Imposto sobre Serviços é responsável por uma grande parte da receita do município. 
ISS - IMPOSTO SOBRE SERVIÇO: LEGISLAÇÃO E ARRECADAÇÃO NO MUNICÍPIO DE BACABAL/MA

Palavras-chave: Imposto sobre serviços. Arrecadação tributária. Gestão púbica municipal.

\section{ABSTRACT}

The Tax on Services is a tax under municipal and Federal District jurisdiction, having the provision of services as a taxable event, the service provider as a taxpayer and the price of the service as a tax base. The study of this theme is relevant and current because it leads us to deepen the Tax on Services, its legislation and the way it is collected. Its main objective is to present the relevant legislation and collection in the municipality of Bacabal - MA, supported by the specific objectives of identifying the amounts collected on the transparency portal, describing the legislation and demonstrating the importance of this tax for the municipality. Aiming thus to answer the question: How is the Tax on Services regulated and collected in the municipality of Bacabal - MA? The studies and considerations in this article go through the conceptualization of the sciences of taxes, Public Administration and municipal legislation. We based the bibliographic and documentary research with authors such as Crepaldi (2017), Hack (2013), Gomes (2010), as well as legislation such as Complementary Law no 116, the Federal Constitution of 1988, other state and municipal laws and also the portal data of transparency of the municipality and the Brazilian Institute of Geography and Statistics. The Service Tax in the municipality of Bacabal MA is governed by Law 1082 of 2008 which provides for municipal taxes, collection and aliquot and other observations. According to data found in the survey on the 
municipality's transparency portal, the Services Tax is responsible for a large part of the municipality's revenue. Keywords: Tax over services. Tax collection. Municipal public management.

\section{INTRODUÇÃO}

$\mathrm{Na}$ Constituição Federal de 1988, p.70, o Imposto sobre Serviços encontra-se definido como de competência municipal e do Distrito Federal conforme encontramos no artigo abaixo:

"Art. 156. Compete aos Municípios instituir impostos sobre: III - serviços de qualquer natureza, não compreendidos no art. 155, II, definidos em lei complementar".

O Imposto sobre Serviços de qualquer natureza é um tributo que juntamente com outros são arrecadados pelos munícipios para financiar as despesas públicas. Para esse imposto o prestador de serviço é o contribuinte e o valor do imposto tem por base o valor do serviço.

Este estudo pretende apresentar os conceitos e bases do Imposto sobre Serviço de qualquer natureza, que nessa pesquisa é tratado com a nomenclatura de Imposto sobre serviço. Traz como objetivo principal 
ISS - IMPOSTO SOBRE SERVIÇO: LEGISLAÇÃO E ARRECADAÇÃO NO MUNICÍPIO DE BACABAL/MA

apresentar a legislação pertinente e arrecadação no município de Bacabal - MA complementado pelos objetivos específicos de identificar no portal de transparência do município os valores arrecadados desse tributo, fazer uma descrição da legislação e demonstrar qual a importância desse imposto para a gestão dos municípios. Pretendendo assim responder 0 questionamento: Como é regido e arrecadado o Imposto sobre Serviços no município de Bacabal - MA?

A escolha da pesquisa desse tributo nos traz a compreensão e esclarece que o Imposto sobre Serviço pode vir a ser a maior fonte de valores para a receita pública dos municípios, embora na legislação os impostos não tenham contra prestação, sendo o valor arrecadado utilizado pra fins diversos.

Os estudos, considerações e pesquisa bibliográfica se organizam pela conceituação dos tributos, legislação tributária municipal e arrecadação do Imposto sobre Serviços. A metodologia bibliográfica e documental tem base em autores como Crepaldi (2017), Hack (2013), Gomes (2010), a Lei Complementar ํㅜ116, a Constituição Federal de 1988, a Lei Orgânica do Município, o Código 
ISS - IMPOSTO SOBRE SERVIÇO: LEGISLAÇÃO E ARRECADAÇÃO NO MUNICÍPIO DE BACABAL/MA

Tributário Nacional, lei 5.172, o Código Tributário Municipal, lei 1082, o portal de transparência do município, os dados disponibilizados pelo Instituto Brasileiro de Geografia e Estatística, assim como outros estudiosos e outras leis.

O Imposto sobre serviço no município de BacabalMA é regido pela Lei 1082 de 2008 que dispõe sobre os tributos municipais, criada com base no Código Tributário Nacional. No texto da lei citada o fato gerador do imposto é a prestação de serviço, dispostos e descritos em lista anexa a lei, executado por pessoa física, jurídica, profissional autônomo ou empresa e a base de cálculo é o valor do serviço. Em relação à alíquota a lei é complementada por alguns anexos, e no anexo I encontramos descrição de serviços com os percentuais de $5 \%$ para a maioria dos serviços e $3 \%$ e $2 \%$ para outros serviços listados.

O Imposto sobre Serviços juntamente como os outros impostos municipais são responsáveis por uma grande parte da receita dos municípios. E o município de Bacabal possui legislação especifica que organiza esse imposto sua alíquota e arrecadação. A gestão municipal 
disponibiliza no seu portal de transparência a todos os munícipes a previsão e o valor de arrecadado mensalmente e anualmente do Imposto sobre serviços.

\section{ADMINISTRAÇÃO PÚBLICA TRIBUTÁRIA}

A Administração Pública é o aparelhamento do Estado, que é organizado para a realização de todos os seus serviços, visando à satisfação das necessidades do povo.

A Administração Pública, que pode ser
definida como o conjunto de órgãos,
agentes e pessoas jurídicas responsáveis
pelo desenvolvimento da atividade
administrativa, atua de forma direta ou
centralizada, através de seus órgãos, ou de
forma indireta ou descentralizada, quando
cria ou autoriza a criação de outras pessoas
jurídicas para lhe auxiliarem em tal tarefa
(AMADO, 2019 p.361).

Segundo Paludo (2012) o sentido amplo compreende tanto o governo - responsável por tomar as decisões políticas - a estrutura administrativa, bem como à administração - que executa essas decisões. Já o sentido estrito compreende apenas as funções 
administrativas relacionadas à execução dos programas de governo, prestação de serviços e demais atividades.

A administração tributária da União, Estados, Distrito Federal e Municípios são orientados pelo Código Tributário Nacional do ano de 1966, pela Emenda no 18 de 1965 e outras leis estaduais e municipais que dispõem sobre contribuintes, fato gerador e alíquotas.

Essa administração corresponde a uma parte da Administração Pública, a da atividade financeira do Estado. Assim ele regula, controla, acompanha e fiscaliza a aplicação e arrecadação dos tributos, visando assim à receita pública.

Na Lei Orgânica do município de Bacabal de 1990, no título IV que trata da competência financeira traz no texto o tratamento da Administração Tributária Municipal:

\footnotetext{
Art.121 - A Administração Tributária é atividade vinculada, essencial ao Município e deverá estar dotada de recursos humanos e materiais necessários ao fiel exercício de suas atribuições, principalmente ao que e refere:

I - lançamento dos tributos;

II - cadastramento dos contribuintes e das atividades econômicas;

III - fiscalização de cumprimento das obrigações tributárias;
} 
IV - inscrição dos inadimplentes em dívida ativa e respectiva cobrança amigável ou encaminhamento para a cobrança judicial (Lei Orgânica do Município de Bacabal, 1990 p.32).

Os municípios são responsáveis pela legislação, arrecadação e administração dos tributos que a lei que a lei descreve como autonomia destes. Gerando assim sua receita de acordo com as atividades desenvolvidas no âmbito municipal.

\section{IMPOSTO SOBRE SERVIÇO}

\subsection{Legislação do Imposto sobre Serviços}

Segundo Barreto (2005), o Imposto sobre Serviços, por ser uma das principais fontes da arrecadação financeira municipal, se expandiu por todo o território depois da Constituição de 1988 que definiu a criação de lei orgânica para cada município. Aumentando ainda mais essa expansão a lei complementar no116 de 2003 traz a obrigação de criar leis para cada município para a gestão dos impostos que lhes compete.

No Código Tributário Nacional, lei oㅜ 5.172 encontrase a definição de um dos tipos de tributo, o imposto: 
Art. 16. Imposto é o tributo cuja obrigação tem por fato gerador uma situação independente de qualquer atividade estatal específica, relativa ao contribuinte (Código Tributário Nacional, 1966, p.3).

A Lei Complementar no 116 de 2003 dispõe detalhadamente sobre o Imposto sobre Serviços e outras providências sobre aplicação, cálculos e competência. Estabelece 0 caput do art. $1^{\circ}$ da Lei Complementar 116/2003 que:

O Imposto Sobre Serviços de Qualquer Natureza, de competência dos Municípios e do Distrito Federal, tem como fato gerador a prestação de serviços constantes da lista anexa, ainda que esses não se constituam como atividade preponderante do prestador (LC 116/2003 p.1).

Em conformidade com 0 art. $1^{\circ}, \S 3^{\circ}$, da Lei Complementar 116/2003, o Imposto sobre Serviços incide também sobre os serviços prestados mediante a utilização de bens e serviços públicos que são explorados economicamente com autorização, permissão ou concessão, e com o pagamento de tarifas, preços ou pedágios pelo usuário final do serviço.

Segundo Hack (2013 p.87), é um imposto municipal com caráter fiscal. Tem como hipótese de incidência a prestação de serviços, excluindo-se aqueles sujeitos ao 
Imposto sobre Circulação de Mercadorias e Serviços. Assim pode ser cobrado o valor fixo quando se trata de trabalho de profissionais liberais ou pode ter como base de cálculo o valor do serviço.

No ano de 2016 surgiu a lei complementar nำ157 que trouxe um aspecto que causou e causa impacto nas organizações, que é a responsabilidade dos tomadores de serviço realizar a retenção na fonte e depois repassar aos municípios, o que antes não ocorria agora pode ser executado, ficando a arrecadação na responsabilidade do tomador de serviço.

No Código Tributário Nacional encontra-se taxadas as descrições dos impostos que são de responsabilidade dos estados e municípios. Cada estado legisla sobre seus impostos estaduais e cada município legisla sobre os impostos de sua competência.

A Lei Municipal n 1082 de 2008, o Código Tributário Municipal de Bacabal, em seu Artigo 6, inciso I, alínea c descreve o Imposto sobre Serviço:

Art. 6.ㅇ O sistema tributário municipal é composto por:

I - impostos:

[...] 
c) sobre serviços de qualquer natureza, não compreendidos no inciso II do art. 155, da Constituição da República Federativa do Brasil, definidos em lei complementar federal;

O conceito de imposto sobre serviços de qualquer natureza no Código Tributário Municipal tem a mesma descrição que no Código Tributário Nacional assim como o fato gerador que é a prestação de serviço por pessoa física ou jurídica, profissional autônomo ou empresa.

Encontramos no Artigo 40 do Código Tributário Municipal:

§ 3o A caracterização do fato gerador do Imposto Sobre Serviços de Qualquer Natureza - ISSQN não depende da denominação dada ao serviço prestado ou da conta utilizada para registros da receita, mas, tão-somente, de sua identificação, simples, ampla, analógica ou extensiva, com os serviços previstos na lista de serviços (CTM, 2008 p.15).

Nas duas legislações, Código Tributário Nacional e Código Tributário Municipal, constam uma lista em anexo descrevendo o rol de tipos de serviços. Os serviços provenientes do exterior também sofrem a incidência deste imposto. 
ISS - IMPOSTO SOBRE SERVIÇO: LEGISLAÇÃO E ARRECADAÇÃO NO MUNICÍPIO

\subsection{Arrecadação do Imposto sobre Serviços}

Segundo Magieri (2001, p. 35), desde a Roma antiga, nos tempos do imperador Constantino, havia a existência da cobrança de impostos sobre serviços. $E$ essa prática foi organizada em legislação e executada pelos países em função de obtenção de receita pública.

A arrecadação do Imposto sobre serviços é realizada pelas prefeituras municipais sendo exigida por lei, a Lei de Acesso à Informação, a disponibilização dos dados no Portal de Transparência dos municípios.

De acordo com o CTN - Código Tributário Nacional, contribuinte é a pessoa física ou jurídica, que tem relação com a situação que constitua o fato gerador do imposto, ou seja, que efetue a prestação dos serviços. Uma vez que ocorra o fato gerador, o prestador de serviço formal ou informal tem possibilidade de cumprir com a obrigação de pagar o imposto.

O fato gerador do Imposto sobre Serviços é a prestação do serviço, o artigo 39 do Código Tributário Municipal também faz menção a uma lista de serviços anexa a lei, onde estão divididos os serviços e os similares 
e a alíquota para cada um. E no parágrafo terceiro do artigo 40 é esclarecido que essa lista comporta interpretação ampla, analógica e extensiva na sua horizontalidade. Ou seja, que ela seguida por cada profissional que exerça a atividade constante nela e que cumpra seu papel de contribuinte.

§ $3^{\circ}$ A caracterização do fato gerador do Imposto Sobre Serviços de Qualquer Natureza - ISSQN não depende da denominação dada ao serviço prestado ou da conta utilizada para registros da receita, mas, tão-somente, de sua identificação, simples, ampla, analógica ou extensiva, com os serviços previstos na lista de serviços (Lei Municipal № 1082 de 2008, p.15).

Através da lista de serviços é possível identificar a descrição dos serviços e suas ramificações e o percentual instituído pelo código municipal. Assim empresas prestadoras de serviços e prestadores de serviços podem efetuar o pagamento desse imposto quando emitem a nota fiscal de serviço.

Segundo o Código Tributário Municipal as alíquotas variam de acordo com os serviços, estes estão em lista anexa ao código, a maioria dos serviços e suas ramificações são cobradas a alíquota de $5 \%$; já para 
serviços de saúde e de assistência médica irão pagar 3\%; os serviços de estética, cuidados pessoais e atividades físicas também entram na tabela dos 3\%; os serviços de bens relacionados a terceiros e suas descrições também constam na tabela com a alíquota de 3\%; assim como pagam apenas 3\% os serviços de orientação pedagógica, instrução e treinamento pessoal; e apenas os serviços que se encaixam na tabela com a alíquota de $2 \%$ são os serviços de transporte de natureza municipal.

A arrecadação desse imposto é de responsabilidade da secretária de finanças do município que faz as atividades de cadastro do contribuinte, emissão de notas fiscais de serviços e arrecadação dos tributos.

No portal de transparência do município, encontramos disponibilizado a todos os cidadãos, as receitas a descrição do Imposto sobre serviços de qualquer natureza com os valores previstos e valores arrecadados.

Mas não consta todos os anos, o sistema não disponibiliza nem os três últimos, e nem informa o motivo da falta de dados. Atribuímos a ocorrência devido à 
mudança de gestão juntamente com a administração das informações.

Observou-se que a cada mandato é desenvolvido e gerido um site novo e as informações financeiras de receitas e despesas que deveriam obedecer a uma ordem cronológica se perdem nas falhas da gestão dessas informações.

Constando no momento dessa pesquisa apenas dados soltos de alguns anos anteriores, e instabilidade na manutenção e sustentação da página na internet, uma vez que nas várias tentativas no decorrer da pesquisa houve falhas no site e em outros momentos a janela estava indisponível.

Os dados no quadro abaixo foram extraídos do site atual da prefeitura, na aba do portal de transparência atual e, por conseguinte do portal de transparência da gestão anterior, e complementado com os dados disponibilizado no site do IBGE - Instituto Brasileiro de Geografia e Estatística. 
ISS - IMPOSTO SOBRE SERVIÇO: LEGISLAÇÃO E ARRECADAÇÃO NO MUNICÍPIO DE BACABAL/MA

Quadro 1 - Quadro demonstrativo de Arrecadação

\begin{tabular}{|c|c|c|}
\hline ANO & VALOR PREVISTO & VALOR ARRECADADO \\
\hline 2014 & & $\mathrm{R} \$ 4.179 .000,00$ \\
\hline 2015 & & $\mathrm{R} \$ 5.422 .881,31$ \\
\hline 2016 & & $\mathrm{R} \$ 4.754 .331,43$ \\
\hline 2017 & $\mathrm{R} \$ 3.900 .000,00$ & $\mathrm{R} \$ 5.167 .301,91$ \\
\hline 2018 & $\mathrm{R} \$ 4.673 .350,00$ & $\mathrm{R} \$ 1.797 .540,66$ \\
\hline $1^{\circ}$ trimestre de 2019 & & \\
\hline
\end{tabular}

Fonte: https://cidades.ibge.gov.br/Portal de transparência do município de Bacabal.

No quadro encontramos que os valores arrecadados ficam com os valores próximos de um ano para outro, e observa-se uma queda, se compararmos à média dos anos anteriores em relação ao ano de 2018.

No ano citado o município passou por novas eleições, ficando os dois anos anteriores a 2018 sendo gerido ora por uma gestão, ora por outra. Atribuímos a essa troca de gestão as falhas nas informações e na transparência da administração dos recursos financeiros, assim como no planejamento do município.

Como o Imposto sobre serviços é responsável por uma boa fatia da receita do munícipio, observou-se que poderia ser maior a arrecadação uma vez que existe o fator crescente e corrente que são os trabalhadores 
ISS - IMPOSTO SOBRE SERVIÇO: LEGISLAÇÃO E ARRECADAÇÃO NO MUNICÍPIO DE BACABAL/MA

informais, e que muitos destes deixam de cumprir essa obrigação tributária. E que os valores dos anos anteriores estavam em uma crescente que só viriam a aumentar a receita pública e, por conseguinte a aplicação desse recurso no município.

É necessária na prestação dos serviços a emissão da nota fiscal pelo portal da prefeitura, quando já possui o cadastro, ou quando não possuir, o prestador de serviço ou a empresa de serviços pode solicitar na secretária de finanças mediante os dados do prestador de serviço ou da empresa e os valores, assim o órgão pode fazer a emissão da nota, ou cadastrar no sistema para o profissional ou a empresa fazer as próximas emissões sozinhas.

O município encontra dificuldade, pois não consegue mapear todos os trabalhadores prestadores de serviços, pois todos os dias surgem novos trabalhadores $e$ empresas, e estes, principalmente o prestador do serviço desconhece ou se exime de suas obrigações tributárias. Ficando também a questionarmos sobre a fiscalização e controle dessa arrecadação, e da informação sobre a importância desse tributo. 


\section{CONCLUSÃO}

O Imposto sobre Serviço legislado e arrecadado pelos municípios é fonte de receita pública, ficando como o primeiro imposto mais arrecadado de gestão dos municípios. O referido imposto tem como fato gerador toda prestação de serviço descrita na lista de serviços anexa na legislação do município, executada por pessoa física ou empresas.

É importante a explanação e explicação de legislações e de tributos pagos pelos cidadãos, pois muitos desconhecem as informações, e que embora seja disponibilizado os dados, obrigatoriamente por lei, nos portais de transparências, parte da população não acessa ou desconhece os pormenores das receitas públicas.

O município de Bacabal apesar de possuir seu código tributário, efetuar a arrecadação dos tributos, utilizar a receita pública para o bem comum, ainda é passível de falhas em relação à disponibilização dos valores a comunidade e sobre as informações e educação da população em respeita ao contribuinte, como pudemos comprovar nesta pesquisa. 
O Imposto sobre Serviços é o imposto com uma maior arrecadação no município, deixando para trás outros impostos de competências municipais, como o Imposto sobre a Propriedade Predial e Territorial Urbana e o Imposto de Transmissão de Bens Imóveis e as Taxas administradas pela prefeitura.

Encontramos falhas no município quando se pesquisou a arrecadação desse tributo e nas informações nas disponibilizadas, podendo assim essa pesquisa abrir espaço para reflexão, maiores estudos, revisão do Código Tributário Municipal, assim como educação e o entendimento e cobrança dos contribuintes e munícipes.

Os impostos assim como a administração do munícipio devem ser fiscalizados e acompanhados pela coletividade para uma melhor gestão dessa receita. 


\section{REFERÊNCIAS}

AMADO; Frederico (org.) Técnico do INSS: todas as disciplinas. Salvador: Juspodivm, 2019.

BARRETO, Aires F. ISS na Constituição e na lei. São Paulo: Dialética, 2005.

BACABAL. Lei Orgânica Municipal, de 13 de março de 1990.

BRASIL. Constituição da República Federativa do Brasil (1988). Promulgada em 05 de outubro de 1988.

- Lei Complementar no 116, de 31 de julho de 2003.

. Código de Tributário Nacional. Lei nํ⒌ 172, de 25 de outubro de 1966.

. Lei no 4.729 de 14 de julho de 1965. Define o crime de sonegação fiscal e dá outras providências. . Lei $\mathrm{n}^{\circ} 8.137$ de 27 de novembro de 1990. Define crimes contra a ordem tributária, econômica e contra as relações de consumo, e dá outras providências.

. Decreto no 70.235, de 6 de março de 1972.

Dispõe sobre o processo administrativo fiscal, e dá outras providências. 
ISS - IMPOSTO SOBRE SERVIÇO: LEGISLAÇÃO E ARRECADAÇÃO NO MUNICÍPIO DE BACABAL/MA

CREPALDI, Silvio Aparecido. Planejamento tributário Teoria e Prática. São Paulo: Saraiva, 2017.

GOMES. Francisco J. Aspectos teóricos e práticos do ISS.

São Paulo: Dialética, 2003.Disponível em:

http://governotransparente.com.br/2099490. Acesso em:

18 fev. 2019.

HACK, Érico. Direito Tributário. Curitiba, PR: IESDE Brasil, 2013.

Disponível em:

https://cidades.ibge.gov.br/brasil/ma/bacabal/pesquisa/21

$/ 28141$ ?tipo=ranking\&indicador=28148\&ano=2014 .

Acesso em: 10 fev. 2019.

Lei Municipal no 1082 de 18 de dezembro de 2008. Dispõe sobre o sistema tributário municipal e estabelece normas gerais suplementares em matéria de legislação tributária no município de Bacabal.

MAGIERI, Francisco Ramos. ISS - Teoria Práticas e Questões Polêmicas. São Paulo: Edipro, 2001.

PALUDO, Augustinho. Administração Pública para Auditor Fiscal da Receita Federal e Auditor Fiscal do Trabalho. Rio de Janeiro: Campus-Elsevier, 2012. 